\title{
The Effect of HbA1c Level on Gender-Specific Long-Term Morbidity and Mortality After Isolated Coronary Bypass in Poorly Controlled Diabetic Patients
}

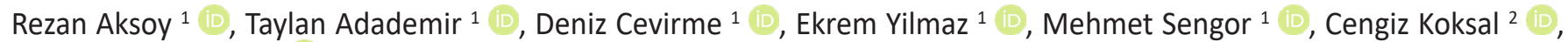 \\ Murat Bulent Rabus ${ }^{1}$ \\ ${ }^{1}$ Department of Cardiovascular Surgery, University of Health Sciences, Kartal Kosuyolu Heart Training and Research Hospital, Istanbul, Turkey. \\ ${ }^{2}$ Bezmialem Vakif University, Medical Faculty Department of Cardiovascular Surgery, Istanbul, Turkey.
}

Correspondence Author: Cengiz Koksal

E-mail: ckoksal@hotmail.com

Received: $20.08 .2020 \quad$ Accepted: 11.02 .2021

\begin{abstract}
Objective: The aim of this study is to evaluate the gender specific effects of the high $\mathrm{HbA1c}$ levels in poorly controlled diabetic patients undergoing isolated coronary artery bypass grafting (CABG) procedure on long term morbidity, mortality and re-revascularization ( $2^{\text {ndintervention). }}$

Methods: This study was conducted on 532 (346 (65\%) males and 186 (35\%) females) diabetic patients who underwent CABG procedure at a single center between January 2010 and December 2013.The patients were separated into 4 groups according to gender and preoperative HbA1c level (\%). The group1 consisted of females with HBA1c level $\leq 7(n=46)$; the group 2 comprised female with HbA1c level $>7(n=140)$; the group 3 comprised men with HbA1c level $\leq 7(n=117)$; and the group 4 comprised men with HbA1c level $>7(n=229)$. The groups were analyzed and compared for postoperative complications and mortality.

Results: No statistically significant difference was found among the groups in $\mathrm{HbA1c}$ levels and gender with respect to postoperative infection and mortality $(p>0.05)$. The HbA1c level was determined to be statically significant and required the $2^{\text {ndintervention }(p: 0.001 ; 95 \% ~ C l: ~} 1.249$ $(1.055,1.478))$.

Conclusion: This study suggested that there was no difference in mortality rates after CABG among the groups although the current risk calculator modules stated otherwise. However, the HbA1c levels were associated with a need for a secondary intervention on long term follow up period.
\end{abstract}

Keywords: Diabetes Mellitus, Coronary Artery Bypass Grafts, Gender

\section{INTRODUCTION}

The ratio of diabetes mellitus (DM) was 23\% among patients undergoing coronary artery bypass graft (CABG)surgery. This percentage is higher in female and currently increasing in both genders [1-3]. Diabetic patients have 2-4 fold higher mortality rate associated with cardiovascular disease as compared with non-diabetic patients, and the morbidity rate is also higher [4].

Hemoglobin A1c (HbA1c) is commonly used as an indicator of long-term average blood glucose levels [5]. $\mathrm{HbA1C}$ is an approved criterion for diagnosis of DM by The American Diabetes Association [6]. Higher levels of HbA1c (> 7\%) have been found to be related to various complications (stroke, myocardial infarction) and increased risk of all-cause mortality following open heart surgery, but gender specific effects of higher levels of $\mathrm{HbA1c}$ are not well sought [7].

In this study, poorly controlled diabetic patients undergoing CABG surgery were retrospectively analyzed. The effect of gender and higher $\mathrm{HbA1c}$ levels on the long term morbidity, mortality and the need for repeat revascularization were studied.

\section{METHODS}

This study was conducted on a total of 532 diabetic cases comprising 346 (65\%) men and 186(35\%) female who underwent isolated CABG at a single center between January 2010 and December 2013. The mean age of the patients was $60.26 \pm 9.32$ years (range, 31-84 years).

The Inclusion criteria were as follows: being diagnosed with uncontrolled diabetes ( $\mathrm{HbA} 1 \mathrm{c}>5,6 \%)$, receiving any kind of treatment for diabetes and undergoing isolated CABG surgery. The patients were separated into 4 groups according to gender and $\mathrm{HbA} 1 \mathrm{c}$ levels. The threshold pre-operative $\mathrm{HbA} 1 \mathrm{c}$ level of $7 \%$ was accepted as a marker of uncontrolled diabetes, according to the current literature $[7,8]$. The group 1 comprised of female with HBA1c level $7 \%(n=46)$; the group 2 comprised of female with HBA1c level $>7 \%(n=140)$; the group 3 comprised of men with HBA1c level $\leq 7 \%(n=117)$; and the group 4 comprised of men with HBA1c level $>7 \%$ $(n=229)$. Additionally, we evaluated the clinical progress of 
the symptoms of coronary artery disease (CAD) in the long term follow up period. The asymptomatic patients had no recurrent symptoms of coronary artery ischemia at followups. The symptomatic patients were those who presented with symptoms of coronary artery disease and underwent coronary angiography but did not require revascularization. Symptomatic patients ( $\mathrm{n}$ : 66, 12.4\%) who had required rerevascularization were classified as the second intervention patients receiving treatment either with redo $\mathrm{CABG}$ or $\mathrm{PCI}(\mathrm{n}$ : $41,7.7 \%)$. Three of symptomatic patients required redo CABG.

Long-term survival results were searched on hospital database, the national health database and phone-calls with the patients. Also, potential second intervention to the patient in another institution was interrogated during these phone-calls. If the second intervention history is positive, detailed information of this second intervention was obtained from the host-institute by phone-calls too. We excluded the patients with the missing data.

The exclusion criteria were as follows: non-diabetic patients and diabetic patients with low HbA1c level (HbA1c 5,6\%) patients with incomplete medical reports, patients using steroids or undergoing chemotherapy, and those receiving a diagnosis of decompensated congestive heart failure, congenital heart disease, cerebrovascular disease within the previous 30 days, dialysis-dependent kidney failure, a clinically active malignancy, endocrinological disorders (hypothyroidism, hyperthyroidism), systemic inflammatory disease, hematological proliferative disease, low hemoglobin levels ( $\mathrm{Hgb} \leq 10 \mathrm{~g} / \mathrm{dl}$ ), a clinically active infection, or a diagnosis of autoimmune disease.

After the local ethical committee approval, the demographic and clinical characteristics were recorded for each patient. Acute kidney injury (AKI) was evaluated and classified according to the Kidney Disease Improving Global Outcomes (KDIGO) classification by calculating preoperative and postoperative serum creatinine levels [9]. Chronic obstructive pulmonary disease (COPD) was defined as follows: - Patients with obstructive pattern in preoperative spirometry (FEV1/ FEVC $<0,70)$. - Patients having active treatment for COPD [10].

DM was accepted as the use of oral anti-diabetic drugs or insulin or a fasting blood glucose level $>126 \mathrm{mg} / \mathrm{dl}$ [11]. Before the procedure, peripheral venous blood samples (5-7 cc) were obtained and placed in sterile EDTA tubes to prevent clotting. After 1 hour, hematological parameters were calculated with an automatic blood count device (Abbott CELL-DYN 3700; Abbott Laboratory, Abbott Park, Illinois, USA). All patients had oral antidiabetic-drug or insulin. No patient among all 4 groups received both insulin and oral diabetic drugs at the same time. We evaluated preoperative low density lipoprotein level (LDL $>100 \mathrm{mg} / \mathrm{dl}$ and >190 mg/dl) (12).

\subsection{Blood Sugar Examinations}

Throughout the operation, the blood glucose levels of the patients were evaluated once before the CPB and then at hourly intervals. Crystallized insulin (Humulin $R^{\circledR}$, Lilly,
Indianapolis, USA) was applied intravenously to control blood glucose level. In the intensive care unit (ICU), all patients' blood glucose levels were regulated with an insulin infusion according to the Portland protocol [13]. An average glucose level was calculated for each patient.

\subsection{Surgical procedure}

All the surgical procedures were performed as on or off pump during CABG surgery. Following the anesthesia induction median sternotomy was performed in all of the patients. Coronary bypass grafts were harvested from the saphenous vein and the left internal mammary artery (pediculate). A non-pulsatile roller pump and membrane oxygenator was used for cardiopulmonary bypass (CPB) in on-pump CABG patients. The surgical procedure was performed at moderate systemic hypothermia $\left(28^{\circ} \mathrm{C}-30^{\circ} \mathrm{C}\right)$. CPB was applied at a flow rate of $2.2-2.5 \mathrm{~L} / \mathrm{min} / \mathrm{m}^{2}$. Mean arterial pressure between $50-80 \mathrm{mmHg}$ and hematocrit values of $20 \%$ $25 \%$ were achieved in all patients. Myocardial protection was applied with intermittent antegrade and continuous retrograde hypothermic and hyperkalemic blood cardioplegia. The proximal anastomoses were performed on beating heart under a partial clamp. Additionally; electrocardiogram (ST segments), mean arterial pressure $(>70 \mathrm{mmHg})$, cardiac output and activated clotted time (ACT > 250 seconds) monitored continuously during the off-pump CABG procedure.

\subsection{Statistical Analyses}

For the statistical analysis, NCSS 2007 software was used (Number Cruncher Statistical System, Kaysville, Utah, USA). Descriptive statistical methods such as mean, standard deviation, median, the first quartile, the third quartile, frequency, and percentage, minimum, maximum were used for reporting the data. Independent samples t-test was used to compare normally distributed variables between the 2 groups, Mann-Whitney U-test was used for variables violating normal distribution assumption. One-way ANOVA with Tukey HSD post hoc tests were used to compare normally distributed variables between 3 or more groups. Kruskal-Wallis test with Dunn-Bonferroni post hoc tests were used to compare non-normally distributed variables between 3 or more groups. The Pearson chi-square test, the FisherFreeman-Halton exact test, the Fisher's exact test were used to compare qualitative data. Pearson correlation analysis was used to assess the correlation between quantitative variables. The effects of risk factors on postoperative infection and mortality were evaluated via binary backward logistic regression analysis, whereas effects of risk factors on the second intervention were evaluated via multivariate backward logistic regression analysis. The effects of risk factors on length of ICU stay, length of hospital stay and chest tube output were evaluated via linear regression analysis. A p value of $<0.05$ was accepted as statistically significant. 


\section{RESULTS}

The distributions of the descriptive, the preoperative and postoperative characteristics are shown in Table 1. Among 532 cases included in the study, 467 (87.8\%) survived, and 65 died. The CABG procedures were performed with on-pump procedure in 471 patients and on off-pump strategy in 61 patients.
The mean survival time was $72.29 \pm 1.00$ months. The latest death occurred at 77.1 months, and in that month, the cumulative survival rate was $86.1 \%$, with a standard error of 2.0\%. These results are shown according to groups in Figure 1.

Table 1. Comparison according to Gender\& HbA1c levels

\begin{tabular}{|c|c|c|c|c|c|c|c|}
\hline \multirow{3}{*}{ Gender } & & \multirow{2}{*}{\begin{tabular}{|l} 
Total \\
$(n=532)$
\end{tabular}} & \multirow{2}{*}{$\begin{array}{l}\text { Female \& } \\
\text { HbA1c } \% 7 \\
(n=46) \\
46(100) \\
\end{array}$} & \multirow{2}{*}{$\begin{array}{l}\text { Female \& } \\
\text { HbA1c>\%7 } \\
(n=140) \\
140(100) \\
\end{array}$} & \multirow{2}{*}{$\begin{array}{l}\text { Male \& HbA1c } \leq \% 7 \\
(n=117) \\
0(0)\end{array}$} & \multirow{2}{*}{$\begin{array}{l}\text { Male \& HbA1c>\%7 } \\
\text { (n=229) } \\
0(0)\end{array}$} & \multirow{2}{*}{$\begin{array}{l}\mathbf{P} \\
-\end{array}$} \\
\hline & Female & & & & & & \\
\hline & Male & $346(65)$ & $0(0)$ & $0(0)$ & $117(100)$ & $229(100)$ & \\
\hline \multicolumn{2}{|l|}{ HbA1c (\%) } & $8,74 \pm 1,74$ & $6,880 \pm 0,29$ & $9,58 \pm 1,6$ & $6,98 \pm 0,27$ & $9,47 \pm 1,5$ & - \\
\hline \multicolumn{2}{|l|}{ Age (years) } & $60,26 \pm 9,32$ & $61,87 \pm 8,55$ & $62,08 \pm 9,05$ & $61,15 \pm 9,7$ & $58,36 \pm 9,13$ & ${ }^{a} 0,001^{*}$ \\
\hline \multicolumn{2}{|l|}{ BMI $\left(\mathrm{kg} / \mathrm{m}^{2}\right)$} & $29,3 \pm 4,82$ & $31,15 \pm 6,11$ & $29,95 \pm 5,37$ & $29,19 \pm 4,47$ & $28,58 \pm 4,19$ & ${ }^{a} 0,002^{*}$ \\
\hline \multicolumn{2}{|l|}{ Previous MI } & $223(41,9)$ & $14(30,4)$ & $61(43,6)$ & $44(37,6)$ & $104(45,4)$ & ${ }^{\mathrm{b}} 0,196$ \\
\hline \multicolumn{2}{|l|}{ COPD } & $73(13,7)$ & $3(6,5)$ & $22(15,7)$ & $21(17,9)$ & $27(11,8)$ & ${ }^{\mathrm{b}} 0,174$ \\
\hline \multicolumn{2}{|l|}{\begin{tabular}{|l} 
Hypertension \\
\end{tabular}} & $300(56,4)$ & $34(73,9)$ & $98(70)$ & $66(56,4)$ & $102(44,5)$ & ${ }^{b}<0,001^{*}$ \\
\hline \multirow{2}{*}{\multicolumn{2}{|c|}{\begin{tabular}{|l|} 
PVD \\
EF (\%) \\
\end{tabular}}} & $26(4,9)$ & $1(2,2)$ & $3(2,1)$ & $6(5,1)$ & $16(7)$ & ${ }^{b} 0,159$ \\
\hline & & $54,02 \pm 11,15$ & $57,8 \pm 9,44$ & $55,5 \pm 10,39$ & $54,71 \pm 11,12$ & $52,01 \pm 11,59$ & ${ }^{\mathrm{a}} 0,001^{*}$ \\
\hline \multicolumn{2}{|l|}{ LDL > 100; n (\%) } & $335(65,6)$ & $33(73.3)$ & $87(63)$ & $84(73.7)$ & $131(60.1)$ & 0.053 \\
\hline \multicolumn{2}{|l|}{ LDL > 190; n (\%) } & $34(6,6)$ & $3(6.7)$ & $7(5.1)$ & $9(7.9)$ & $15(6.9)$ & ${ }^{\circ} 0.835$ \\
\hline \multicolumn{2}{|l|}{ Critical stenosis } & $6(1,1)$ & $0(0)$ & $2(1,4)$ & $0(0)$ & $4(1,7)$ & ${ }^{\circ} 0,574$ \\
\hline \multicolumn{2}{|l|}{ LIMA used } & 484 (91) & $41(89,1)$ & $128(91,4)$ & $107(91,5)$ & $208(90,8)$ & bo,967 \\
\hline \multicolumn{2}{|l|}{ Reoperation } & $11(2,1)$ & $1(2,2)$ & $5(3,6)$ & $2(1,7)$ & $3(1,3)$ & ${ }^{\circ} 0,463$ \\
\hline \multirow[t]{2}{*}{ DM treatment } & OAD & $403(75,8)$ & $39(84,8)$ & $89(63,6)$ & $101(86,3)$ & $174(76)$ & ${ }^{b}<0,001^{*}$ \\
\hline & Insulin & $129(24,2)$ & $7(15,2)$ & $51(36,4)$ & $16(13,7)$ & $55(24)$ & \\
\hline \multirow[t]{2}{*}{ AKI } & 0 & $357(67,1)$ & $28(60,9)$ & $83(59,3)$ & $85(72,6)$ & $161(70,3)$ & ${ }^{\mathrm{b}} 0,061$ \\
\hline & 1 & $175(32,9)$ & $18(39,1)$ & $57(40,7)$ & $32(27,4)$ & $68(29,7)$ & \\
\hline \multicolumn{2}{|c|}{ Length of ICU stay (hours) } & $44(25-69)$ & $47,5(25-95)$ & $41(23-49)$ & $46(24-75)$ & $46(24-72)$ & ${ }^{d} 0,010^{*}$ \\
\hline \multicolumn{2}{|c|}{ Length of hospitalstay (days) } & $7,5(6-12)$ & $8(7-11)$ & $7(6-10)$ & $7(7-11)$ & $7(7-11)$ & ${ }^{d} 0,251$ \\
\hline \multicolumn{2}{|c|}{ Followupperiod (months) } & $50,9(43,5-68,4)$ & $\begin{array}{l}54,07(43,65- \\
71,08)\end{array}$ & $57,27(42,73-71,5)$ & $54,67(42,5-69,33)$ & $55,13(42,87-69,93)$ & ${ }^{d} 0,867$ \\
\hline \multicolumn{2}{|c|}{ Intubationduration (hours) } & $11(8-16)$ & $11,5(8-16)$ & $9(8-12)$ & $10(8-13)$ & $10(8-13,5)$ & ${ }^{d} 0,004^{*}$ \\
\hline \multirow{2}{*}{\multicolumn{2}{|c|}{ Number of distal bypass grafts }} & $3(2-3)$ & $3(2-3)$ & $3(2-3)$ & $3(2-4)$ & $3(2-3)$ & ${ }^{d} 0,008^{*}$ \\
\hline & Chesttubeoutput (ml) & $550(400-700)$ & $450(350-600)$ & $550(450-800)$ & $600(450-800)$ & $550(400-775)$ & ${ }^{d}<0,001^{*}$ \\
\hline \multicolumn{2}{|c|}{ Perfusionduration (minutes) } & $82,5(49-94)$ & $91(64-115,5)$ & $81(58-102)$ & $90(62-112)$ & $88(61,5-109,5)$ & do,076 \\
\hline \multicolumn{2}{|l|}{ ACC (minutes) } & $48,5(30-64)$ & $50(33,5-70)$ & $48(30-64)$ & $52(35-70)$ & $50(33-68)$ & ${ }^{d} 0,249$ \\
\hline Post-op infectio & & $56(10,5)$ & $4(8,7)$ & $20(14,3)$ & $11(9,4)$ & $21(9,2)$ & ${ }^{b} 0,412$ \\
\hline Mortality & & $65(12,2)$ & $5(10,9)$ & $21(15)$ & $13(11,1)$ & $26(11,4)$ & ${ }^{b} 0,710$ \\
\hline $2^{\text {nd }}$ Intervention & Symptomatic (-) & $425(79,9)$ & $37(80,4)$ & $106(75,7)$ & $98(83,8)$ & $184(80,3)$ & ${ }^{\mathrm{b}} 0,300$ \\
\hline & Symptomatic (+) & $66(12,4)$ & $5(10,9)$ & $17(12,1)$ & $15(12,8)$ & $29(12,7)$ & \\
\hline & $2^{\text {nd }}$ Intervention & $41(7,7)$ & $4(8,7)$ & $17(12,1)$ & $4(3,4)$ & $16(7)$ & \\
\hline
\end{tabular}

BMI: Body Mass Index, MI: Myocardial Infarction, COPD: Chronic Obstructive Pulmonary Disease, PVD: Peripheral Vascular Disease, EF: EjectionFraction, HbA1c: Glycosylated Hemoglobin, LIMA: Left Internal Mammarian Artery, DM: Diabetes Mellitus ICU:Intensive Care Unit, ACC: Aortic Cross Clamp AKI: Acutekidneyinjury LDL: Low Dansity Lipoprotein; ${ }^{a}$ One-way ANOVA (reported as mean \pm sd); ${ }^{b}$ Pearsonchi-square test (reported as $n$ (\%)); ${ }^{c}$ Fisher-FreemanHaltonexact test (reported as $n(\%)) ;{ }^{d}$ Kruskal-Wallis test (reported as median (Q1-Q3)); Q1:First quartile, Q3:Third quartile; * $p<0,05$

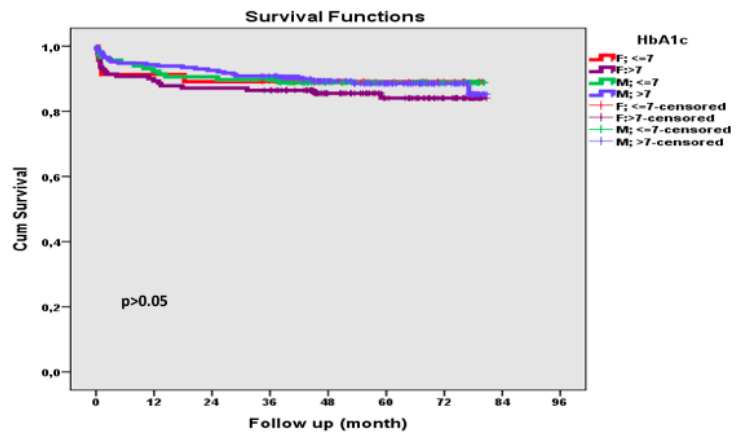

Figure 1. Survival graphic according to HbA1c levels
No statistically significant difference was determined among the groups regarding postoperative infection, mortality and the $2^{\text {nd }}$ intervention ( $p>0.05$ ). The AKI, age, COPD, the length of ICU and the number of distal bypass grafts were found to be statistically significant in mortality $(p<0.05)$. The length of hospital stay was significantly associated with infection $(p<0.05)$. There were no statically significant differences in LDL parameters among the groups $(p<0.05)$.

The postoperative infection, mortality and the $2^{\text {nd }}$ intervention were evaluated according to the characteristics (shown in Table 2). 
Table 2. The patients'scharacteristics determined mortality, infection and the second intervention

\begin{tabular}{|c|c|c|c|c|c|c|c|c|c|c|c|}
\hline & & PostopInfectic & & & Mortality & & & $2^{\text {nd }}$ Interventi & ion & & \\
\hline & & & Yes & $\mathbf{P}$ & No & Yes & $\mathbf{P}$ & $S(-)$ & $S(+)$ & $2^{\text {nd }}$ Int. & $p$ \\
\hline Age (years) & & $60,12 \pm 9,29$ & $61,45 \pm 9,54$ & e0,313 & $59,5 \pm 8,95$ & $65,71 \pm 10,15$ & ${ }^{e}<0,001^{*}$ & $60,48 \pm 9,29$ & $60,17 \pm 9,18$ & $58,12 \pm 9,82$ & 0,303 \\
\hline $\mathrm{BMI}\left(\mathrm{kg} / \mathrm{m}^{2}\right)$ & & $29,25 \pm 4,8$ & $29,66 \pm 5,04$ & $e^{e} 0,553$ & $29,28 \pm 4,73$ & $29,38 \pm 5,5$ & e 0,887 & $29,28 \pm 4,87$ & $29,06 \pm 4,06$ & $29,86 \pm 5,49$ & 0,697 \\
\hline Previous MI & No & $268(86,7)$ & $41(13,3)$ & $0,015^{*}$ & $270(87,4)$ & $39(12,6)$ & b 0,738 & $250(80,9)$ & $36(11,7)$ & $23(7,4)$ & 0,778 \\
\hline & Yes & $208(93,3)$ & $15(6,7)$ & & $197(88,3)$ & $26(11,7)$ & & $175(78,5)$ & $30(13,5)$ & $18(8,1)$ & \\
\hline COPD & No & $415(90,4)$ & $44(9,6)$ & ${ }^{b} 0,076$ & $410(89,3)$ & $49(10,7)$ & $0,006^{*}$ & $367(80)$ & $55(12)$ & $37(8,1)$ & 0,597 \\
\hline & Yes & $61(83,6)$ & $12(16,4)$ & & $57(78,1)$ & $16(21,9)$ & & $58(79,5)$ & $11(15,1)$ & $4(5,5)$ & \\
\hline Hypertension & No & $208(89,7)$ & $24(10,3)$ & ${ }^{b} 0,905$ & $207(89,2)$ & $25(10,8)$ & 0,372 & $187(80,6)$ & $30(12,9)$ & $15(6,5)$ & 0,625 \\
\hline & Yes & $268(89,3)$ & $32(10,7)$ & & $260(86,7)$ & $40(13,3)$ & & $238(79,3)$ & $36(12)$ & $26(8,7)$ & \\
\hline PVD & No & $453(89,5)$ & $53(10,5)$ & 0,747 & $445(87,9)$ & $61(12,1)$ & 80,544 & $403(79,6)$ & $63(12,5)$ & $40(7,9)$ & ${ }^{\circ} 0,932$ \\
\hline & Yes & $23(88,5)$ & $3(11,5)$ & & $22(84,6)$ & $4(15,4)$ & & $22(84,6)$ & $3(11,5)$ & $1(3,8)$ & \\
\hline EF (\%) & & $53,94 \pm 11,28$ & $54,77 \pm 10$ & e,598 & $54,27 \pm 11,27$ & $52,28 \pm 10,13$ & e 0,178 & $54,28 \pm 11,03$ & $51,44 \pm 11,93$ & $55,51 \pm 10,68$ & 0,105 \\
\hline Critical & No & $470(89,4)$ & $56(10,6)$ & 80,999 & $462(87,8)$ & $64(12,2)$ & 80,544 & $420(79,8)$ & $66(12,5)$ & $40(7,6)$ & ${ }^{\circ} 0,491$ \\
\hline & Yes & $6(100)$ & $0(0)$ & & $5(83,3)$ & $1(16,7)$ & & $5(83,3)$ & $0(0)$ & $1(16,7)$ & \\
\hline LIMA used & No & $42(87,5)$ & $6(12,5)$ & 0,640 & $41(85,4)$ & $7(14,6)$ & 0,600 & $38(79,2)$ & $9(18,8)$ & $1(2,1)$ & 0,144 \\
\hline & Yes & $434(89,7)$ & $50(10,3)$ & & $426(88)$ & $58(12)$ & & $387(80)$ & $57(11,8)$ & $40(8,3)$ & \\
\hline Reoperation & No & $467(89,6)$ & $54(10,4)$ & 0,325 & $458(87,9)$ & $63(12,1)$ & 80,632 & $417(80)$ & $65(12,5)$ & $39(7,5)$ & 0,334 \\
\hline & Yes & $9(81,8)$ & $2(18,2)$ & & $9(81,8)$ & $2(18,2)$ & & $8(72,7)$ & $1(9,1)$ & $2(18,2)$ & \\
\hline DM treatment & OAD & $363(90,1)$ & $40(9,9)$ & 0,425 & $357(88,6)$ & $46(11,4)$ & 0,317 & $327(81,1)$ & $51(12,7)$ & $25(6,2)$ & 0,071 \\
\hline & Insulin & $113(87,6)$ & $16(12,4)$ & & $110(85,3)$ & $19(14,7)$ & & $98(76)$ & $15(11,6)$ & $16(12,4)$ & \\
\hline AKI & 0 & $327(91,6)$ & $30(8,4)$ & $0,023^{*}$ & $330(92,4)$ & $27(7,6)$ & ${ }^{b}<0,001^{*}$ & $284(79,6)$ & $43(12)$ & $30(8,4)$ & 0,666 \\
\hline & 1 & $149(85,1)$ & $26(14,9)$ & & $137(78,3)$ & $38(21,7)$ & & $141(80,6)$ & $23(13,1)$ & $11(6,3)$ & \\
\hline $\begin{array}{l}\text { Intubationdura } \\
\text { (hours) }\end{array}$ & ation & $10(8-13)$ & $12(8-17)$ & $0,035^{*}$ & $10(8-13)$ & $11(8-18)$ & 0,103 & $10(8-14)$ & $10(8-12)$ & $9(8-12)$ & ${ }^{d} 0,369$ \\
\hline $\begin{array}{l}\text { Number of dist } \\
\text { bypass grafts }\end{array}$ & & $3(2-3)$ & $3(2-4)$ & 0,329 & $3(2-3)$ & $3(1-3)$ & $0,028^{*}$ & $3(2-3)$ & $2(1-3)$ & $3(2-4)$ & ${ }^{d} 0,012^{*}$ \\
\hline $\begin{array}{l}\text { Perfusiondurat } \\
\text { (minutes) }\end{array}$ & tion & $87(60-108)$ & $\begin{array}{ll}97,5 & (78,5- \\
116,5) & \end{array}$ & $0,023^{*}$ & $88(63-110)$ & $90(40-109)$ & 0,686 & $90(64-110)$ & $68,5(47-95)$ & $87(64-108)$ & ${ }^{d} 0,005^{*}$ \\
\hline ACC (minutes) & & $49(32-67,5)$ & $56(43-70)$ & 0,141 & $50(35-68)$ & $52(20-70)$ & 0,607 & $51(35-69)$ & $43,5(20-64)$ & $51(38-65)$ & ${ }^{d} 0,044^{*}$ \\
\hline $\begin{array}{l}\text { Length of ICU s } \\
\text { (hours) }\end{array}$ & stay & 45 (24-71) & $47,5(25-97,5)$ & 0,060 & 45 (24-70) & 51 (23-119) & $0,031^{*}$ & $47(24-72)$ & $44(24-52)$ & $42(24-71)$ & $d 0,606$ \\
\hline $\begin{array}{l}\text { Length of hospi } \\
\text { (days) }\end{array}$ & italstay & $7(6-10)$ & $13(8-18,5)$ & $<0,001^{*}$ & $7(7-10)$ & $11(7-19)$ & $<0,001^{*}$ & $7(7-11)$ & $8(7-10)$ & $8(7-11)$ & ${ }^{d} 0,360$ \\
\hline Chesttubeoutp & ut (ml) & $550(400-800)$ & $550(425-700)$ & 0,894 & $550(400-750)$ & $550(350-800)$ & 0,610 & $\begin{array}{ll}550 & (400 \\
800) & \end{array}$ & $\left(\begin{array}{l}550 \\
700)\end{array}\right.$ & $-600 \quad(450$ & $-d^{d} 0,300$ \\
\hline
\end{tabular}

BMI: Body Mass Index, MI: Myocardial Infarction, COPD: Chronic Obstructive Pulmonary Disease, PVD: Peripheral Vascular Disease, EF: Ejection Fraction, HbA1c: Glycosylated Hemoglobin, LIMA: Left Internal Mammarian Artery, DM: Diabetes Mellitus ICU: Intensive Care Unit, ACC: Aortic Cross Clamp AKI: Acutekidneyinjury, $S+$ : patients who had symptoms of coronary artery disease; ${ }^{a}$ One-way ANOVA (reported as mean \pm sd); ${ }^{b}$ Pearsonchi-square test (reported as $n(\%)) ;$ 'Fisher-Freeman-Haltonexact test (reported as $n(\%)$ ); ${ }^{d}$ Kruskal-Wallis test (reported as median (Q1-Q3)); ${ }^{e}$ Independentsamples $t$ test (reported as mean $\pm s d) ;{ }^{f}$ Mann-Whitney $U$ test (reported as median (Q1-Q3)); ${ }^{g}$ Fisher'sexact test (reported as $\left.n(\%)\right) ;$ Q1:First quartile, Q3:Third quartile; ${ }^{*} p<0,05$

There was a statistically significant difference in the need for the second intervention according to number of distal bypass grafts $(p<0.05)$. Also, the patients with the high $\mathrm{HbA} 1 \mathrm{c}$ levels required a higher rate of intervention with time $(p<0.05)$. There was no statistically significant difference in the need for re-intervention between off-pump ( $n: 3,4.9 \%)$ and onpump ( $\mathrm{n}: 38,8.1 \%)$ procedures $(\mathrm{p}=0.066)$.
The risk factors of postoperative infection and mortality were determined with binary logistic regression and for the $2^{\text {nd }}$ intervention with multivariate logistic regression analysis. Gender, $\mathrm{HbA} 1 \mathrm{c}$ and variables with $\mathrm{p}<0.150$ in gender comparisons (age, BMI, HT, PVD, EF, DM treatment, AKI, length of ICU stay, Intubation duration, distal bypass grafts, chest tube output and length of hospital stay) were included 
as independent variables. In addition to these variables, for each dependent variable, the variables with $p<0.150$ in the uni-variable analysis regarding that variable were also included in the corresponding model (Table 3).

The model for postoperative infection was found to be statistically significant $\left(\chi^{2}=33.169, \mathrm{p}<0.001\right)$. Previous $\mathrm{MI}$ and length of hospital stay were found to have significant effect on postoperative infection ( $p=0.022, p<0.001$, respectively).

The model for mortality was found to be statistically significant $\left(\chi^{2}=70.242, p<0.001\right)$. Age, AKI, length of ICU stay,
COPD and number of distal bypass grafts were found to have significant effect on mortality $(p<0.001, p<0.001, p<0.001$, $p=0.043, p=0.005$, respectively).

It was found that the model for the $2^{\text {nd }}$ intervention was statistically significant $\left(\chi^{2}=15.862, p=0.003\right)$. HbA1c level and number of distal bypass grafts were found to have significant effect on the 2 nd intervention ( $p=0.010, p=0.003$, respectively). The one unit changes of $\mathrm{HbA1c}$ levels can increase the $2^{\text {nd }}$ intervention risk by 1.249 times.

Table 3. Logistic regression analyses according to infection, mortality and 2nd intervention

\begin{tabular}{|c|c|c|c|c|}
\hline \multicolumn{2}{|c|}{ Dependentvariable } & Independentvariables & p & OR (95\% Cl) \\
\hline \multirow{3}{*}{\multicolumn{2}{|c|}{ Postopinfection }} & Constant & $<0.001^{*}$ & 0.066 \\
\hline & & Previous MI (no) & $0.022 *$ & $2.116(1.113,4.024)$ \\
\hline & & Length of hospitalstay & $<0.001^{*}$ & $1.072(1.042,1.103)$ \\
\hline \multirow{6}{*}{\multicolumn{2}{|c|}{ Mortality }} & Constant & $<0.001^{*}$ & 0.012 \\
\hline & & Age & $<0.001^{*}$ & $1.07(1.036,1.104)$ \\
\hline & & AKI (1) & $<0.001^{*}$ & $2.905(1.626,5.193)$ \\
\hline & & Length of ICU stay & $<0.001^{*}$ & $1.006(1.003,1.009)$ \\
\hline & & COPD (yes) & $0.043^{*}$ & $2.074(1.022,4.208)$ \\
\hline & & Number of distal bypass grafts & $0.005^{*}$ & $0.667(0.502,0.885)$ \\
\hline \multirow[t]{6}{*}{$2^{\text {nd }}$ intervention } & \multirow[t]{3}{*}{ Symptomatic (+) } & Intercept & $0.042 *$ & - \\
\hline & & HbA1c & 0.347 & $1.075(0.924,1.251)$ \\
\hline & & Number of distal bypass grafts & 0.003* & $0.677(0.523,0.876)$ \\
\hline & \multirow[t]{3}{*}{ 2nd intervention } & Intercept & $<0.001^{*}$ & - \\
\hline & & HbA1c & $0.010^{*}$ & $1.249(1.055,1.478)$ \\
\hline & & Number of distal bypass grafts & 0.995 & $0.999(0.733,1.362)$ \\
\hline
\end{tabular}

MI: Myocardial Infarction, COPD: Chronic Obstructive Pulmonary Disease, HbA1c: Glycosylated Hemoglobin, ICU: Intensive Care Unit, AKI: Acute kidney injury; OR: Odds Ratio; Cl: Confidence Interval; Sypmtomatic (-) wastaken as the reference category for the $2^{\text {nd }}$ Intervention analysis; ${ }^{*} p<0.05$

\section{DISCUSSION}

In this study, the effect of the HbA1c level was investigated on long-term morbidity, mortality and the need for the second intervention following CABG procedure in poorly controlled diabetic patients with respect to male and female patients. The results of the study showed that there was no difference in mortality rates after coronary bypass among the groups with respect to $\mathrm{HbA1c}$ level and gender. However, there was a significantly higher need for the second intervention among patients with high $\mathrm{HbA1c}$ level on long term follow up period.

Hyperglycemia has been shown to expand the infarct field in the myocardium, to impair ischemic preconditions and to increase reperfusion injury [14]. Compared to non-diabetic individuals, diabetic patients are known to have a higher morbidity and mortality rate in coronary artery disease (CAD) $[15,16]$. Diabetes is also an indicator of the development of atherosclerosis and plaque instability. Therefore, and specific to diabetes, the number of vessels affected in CAD is usually more than one, the coronary diameters are small, lesion locations are usually osteal or proximal and completely obstructed, narrowing is more often in the left main artery $[6,17]$, collateral vessel development is impaired [18], and there is greater coronary artery calcification [19]. Similarly, females have coronary arteries of a smaller diameter. Small coronary arteries are more predisposed to occlusion and spasm [20]. The most common cause of death of females worldwide is CAD [21]. However, CAD is seen more often as a male disease than female disease [22]. In the past 10 years, there has been a marked increase in CABG operations in females, and currently, 1 out of every 3 CABG operations is performed on a female patient[23].In this study, females comprised $35 \%$ of the study groups. We did not determined difference among the four groups regarding mortality and the $2^{\text {ndintervention. }}$

In a study by Blankstein et al. who investigated the mortality rates in females, it was reported that female gender was independent risk factors for mortality after CABG. [24]. Ennker et al. stated that there was no effect of gender related to increased risk of CABG operation among females [25]. In our study, gender did not have any effect on mortality rates. 
In our study, based on gender, the mortality rates were $13,9 \%$ for the female group and $11,2 \%$ for the male group, it was not statically different contrary to the widely accepted risk calculators $[19,24]$. Additionally, the length ICU stay and chest tube output were found to be longer for female patients than for the male patients.

Hemoglobin A1c (HbA1c) is an index of long-term average blood glucose levels and outcome predictors in diabetic patients [5,7]. Higher levels of HbA1c have been associated increased major adverse cardiac events and death $(7,26)$. Halko et al. studied 3089 diabetic and non-diabetic patients in a prospective study and they found that HbA1c levels had significant effect on hospital stay, morbidity and mortality. Mortality was found to be increased in those with high $\mathrm{HbA1c}$, $\geq 8.6 \%$ [27]. Robich et al., found poor long-term survival in increased $\mathrm{HbA1C}$ among patients undergoing CABG (ratio of death risk increased by $\% 13$ for every unit increase in HbA1 [28]. Nystrom and colleagues found that high levels of $\mathrm{HbA} 1 \mathrm{c}$ resulted in increased rates of mortality and repeat revascularization on type 1 diabetic patients who underwent CABG within 4,7 years follow up (29). In this study, there was no difference between the groups according $\mathrm{HbA1c}$ levels (HbA1c > 7: 12, 7\%; HbA1c <7: 11, 0\%) for long term mortality. Also one of the findings of this study was that there was a statistically significant higher requirement for the secondary revascularization following coronary bypass in patients who had a high level of HbA1c. Revascularization was provided for these patients following angiography. According to the clinical status of the patients, the revascularization was performed as an angiographic procedure or as a redo CABG.

Some other parameters such as preoperative ventricular function can affect early outcome after CABG (30). We did not observe any effect of EF on adverse outcomes, including mortality.

Previous studies have reported that sternal complications are high in DM patients following CABG operations and that this rate can increase to $10 \%$ [31] and the level of $\mathrm{HbA1c}$ is associated with sternal wound infection (32). Halkos et al. also reported that mortality and sternal infection rates increased with a high HbA1c level [27]. In the current study, contrary to expectations, no statically difference was observed in infection rates with respect to the $\mathrm{HbA1c}$ level and gender among the selected diabetic groups.

Czech et al. examined 2881 DM patients undergoing CABG operation and determined that rates of mechanical ventilation were higher and the length of stay in the ICU was longer in females [19]. In this study, all the patients had DM, and the lengths of stay in the ICU and in the hospital were determined to be statistically significantly longer in females with a high HbA1c level compared to the other groups. Additionally, we found that level of $\mathrm{HbA} 1 \mathrm{c}$ were a risk factor for drainage.

Some studies showed that high level of $\mathrm{HbA} 1 \mathrm{c}$ and diabetes mellitus was associated with increased postoperative AKI after CABG [33-34]. According to the KDIGO 2012 AKI
Guidelines, cardiac surgery with CPB is a $1 \mathrm{~B}$ risk factor (9). Although there is no consensus on $\mathrm{AKI}$ and $\mathrm{Hba1c}$ levels in patients with no known renal disease, $\mathrm{HbA} 1 \mathrm{c}$ of $>7 \%$ is defined as a Class $1 \mathrm{~A}$ risk factor for patients with chronic renal disease [27]. However, some studies noted increased $\mathrm{HbA1c}$ level for AKI following CABG is unclear (32). Additionally, the mortality rate of our patient group with AKI was determined to be severely increased in all groups.

\section{CONCLUSION}

This study showed that higher HbA1c levels have no effect in mortality rates after coronary bypass surgery of poorly controlled diabetic patients although the current risk calculator modules stated otherwise. However, the HbA1c levels have been found to be associated with the need for secondary intervention on long term postoperative period. This group of patients should be treated with aggressive medical therapy for blood glucose level regulation and longterm follow up is required during the postoperative period.

\section{Acknowledgment}

We did not receive any financial support for preparation of this article. We did not have communications with any company during the preparation of this article.

\section{REFERENCES}

[1] Szabo Z, Hakanson E, Svedjeholm R. Early postoperative outcome and medium-term survival in 540 diabetic and 2239 non diabetic patients undergoing coronary artery bypass grafting. Ann ThoracSurg 2002;74:712-719.

[2] Thourani VH, Weintraub WS, Stein B, Gebhart SSP, Craver JM, Ellis LJ, Guyton RA. Influence of diabetes mellitus on early and late outcame after coronary artery bypass grafting. Ann Thorac Surg 1999;67:1045-1052.

[3] Carson JL, Scholz PM, Chen AY, Peterson ED, Gold J, Schneider $\mathrm{SH}$. Diabetes mellitus increases short-term mortality and morbidity in patients undergoing coronary artery bypass graft surgery. J Am Coll Cardiol 2002;40:418-423.

[4] Haffner SM. Coronary heart disease in patients with diabetes. N Engl J Med 2000;342:1040-1042.

[5] Ikeda F, Doi Y, Ninomiya T, Hirakawa Y, Mukai N, Hata J, Shikata K, Yoshida D, Mostsumoto T, Kitazono T, Kiyohara Y. Haemoglobin A1c even within non-diabetic level is a predictor of cardiovascular disease in a general Japanese population: the Hisayama Study. Cardiovasc Diabetol. 2013;12:164.

[6] Natali A, Vichi S, Landi P, Severi S, L'Abbate A, Ferrannini E. Coronary atherosclerosis in type II diabetes: angiographic findings and clinical outcome. Diabetologia 2000;43:632-641.

[7] Zheng, J., Cheng, J., Wang, T., Zhang, Q., \& Xiao, X. Does HbA1c level have clinical implications in diabetic patients undergoing coronary artery bypass grafting? A systematic review and meta-analysis. International Journal of Endocrinol 2017; 1537213

[8] Faritous Z, Ardeshiri M, Yazdanian F, Jalali A, Totonchi Z, Azarfarin R. Hyperglycemia or high hemoglobin A1C: Which one is more associated with morbidity and mortality after 
coronary artery bypass graft surgery? Ann Thorac Cardiovasc Surg 2014; 20: 223-228.

[9] Kidney Disease: Improving Global Outcomes (KDIGO) Acute Kidney Injury Work Group KDIGO Clinical Practice Guideline for Acute Kidney Injury. Kidney Int Suppl. 2012;2:1-138.

[10] Pauwels RA, Buist AS, Calverley PM, Jenkins CR, Hurd SS, GOLD Scientific Committee. Global strategy for the diagnosis, management, and prevention of chronic obstructive pulmonary disease. NHLBI/WHO Global Initiative for Chronic Obstructive Lung Disease (GOLD) Workshop summary. Am J Respir Crit Care Med. 2001 Apr; 163(5):1256-1276.

[11] Genuth S, Alberti KG, Bennett P, Buse J, Defronzo R, Kahn R, Kitzmiller J, Knowler WC, Lebovitz $H$, Lernmark $A$, Nathan D, Palmer J, Rizza R, Saudek C, Shaw J, Steffes M, Stern $M$, Tuomilehto J, Zimmet P. Follow-up report on the diagnosis of diabetes mellitus. The Expert Committee on the Diagnosis and Classification of Diabetes Mellitus. Diabetes Care. 2003;26(11):3160-167.

[12] Catapano, AL, Graham I, De Backer G, Wiklund O, Chapman MJ, Drexel H, Hoes WA, Jennigs CS, Landmesser U, Pedersen TR, Reiner Z, Riccardi G, Taskinen MR, Tokgozoglu L, Verschuren M, Vlachopoulos C, Wood DA, Zamorano JL, Cooney MT, ESC Scientific Document Group. 2016 ESC/EAS guidelines for the management of dyslipidaemias. Eur Heart J. 2016;37(39):2999-3058.

[13] Furnary AP, Wu Y, Bookin SO. Effect of hyperglycemia and continuous intravenous insulin infusions on outcomes of cardiac surgical procedures: the Portland Diabetic Project. Endocr Pract. 2004;10 Suppl 2(Supplement 2):21-33.

[14] Lazar HL. How important is glycemic control during coronary artery bypass? Adv Surg 2012;46:219-35.

[15] The Bypass Angioplasty Revascularization Investigation (BARI) Investigators. Comparison of coronary bypass surgery with angioplasty in patients with multivessel disease. N Engl J Med 1996;335:217-225.Erratum, N Engl J Med 1997;336:147.

[16] Malmberg K, Yusuf S, Gerstein HC, Brown J, Zhao F, Hunt D, Piegas L, Calvin J, Keltaj M, Budaj A. Impact of diabetes on longterm prognosis in patients with unstable angina and non-Qwave myocardial infarction: results of the OASIS (Organization to Assess Strategies for Ischemic Syndromes) Registry. Circulation 2000;102(9):1014-9.

[17] Melidonis A, Dimopoulos V, Lempidakis E, Hatzissavas J, Kouvaras G, Stefanidis A, Foussas S. Angiographic study of coronary artery disease in diabetic patients in comparison with nondiabetic patients. Angiology 1999;50: 997-1006.

[18] Abaci A, Oğuzhan A, Kahraman S, Eryol NK, Unal S, Arinç H, Ergin A. Effect of diabetes mellitus on formation of coronary collateral vessels. Circulation 1999; 99(17):2239-2242.

[19] Czech B, Kucewicz-Czech E, Pacholewicz J, Wojarski J, Puzio J, Przybylski R, Farmas A, Ryfinski B, Zembala M. Original article Early results of coronary artery bypass graft surgery in women. Kardiologia Polska (Polish Heart Journal) 2007;65(6).

[20] Göksedef D, Ömeroğlu S, Balkanay O, Talas Z, Arapi B, Ipek G. Coronary artery bypass in women: what is really different? Turk Gogus Kalp Damar Cerrahisi Dergisi 2012;20(1):8-13 (Turkish)

[21] Rosamond W, Flegal K, Friday G, Furie K, Go A, GreenlundK, Haase N, Ho M, Howard V, Kissela V, Kittner S, Lloyd-Jones D, McDermott M, Meigs J, Moy C, Nichol G, O’Donnell CJ, Roger V, Rumsfeld J, Sorlie P, Steinberger P, Thom T, WasserthielSmoller S, Hong Y.Heart disease and stroke statistics-2007 update; a report from the American Heart Association Statistics Committee and Stroke Statistics Subcommittee. Circulation 2007;115:e169-e171

[22] Marco SB, Kim MF, Silvia GP. Cardiovascular diseases in Women: a statement from the policy conference of the European Society of Cardiology European Heart Journal 2006; 27:994-1005.

[23] Kaya $M$, İyigün $T$, İyigün $M$, Bakır $I$, Yeniterzi $M$. The results of coronary artery surgery in women and men under the age of 45. Turk gogus kalp damar cerrahisi derg. 2013;21(3):581587

[24] Blankstein R, Parker Ward R, Arnsdorf $M$, , Jones B, Lou $Y B$, Pine $M$. Female gender is an independent predictor of operative mortality after coronary artery bypass graft surgery contemporary analysis of 31 midwestern hospitals circulation. 2005; 112:I-323-I-327

[25] Ennker IC, Albert A, Pietrowski D, Bauer K, Ennker J, Florath I. Impact of gender on outcome after coronary artery bypass surgery. Asian Cardiovasc Thorac Ann. 2009;17(3):253

[26] Kuhl J, Sartipy U, Eliasson B, Nystrom T, Holzmann MJ. Relationship between preoperative hemoglobin A1c levels and long-term mortality after coronary artery bypass grafting in patients with type 2 diabetes mellitus. Int J Cardiol 2016; 202:291-296.

[27] Halkos M, Lattouf O, Puskas J, Kilgo P, Cooper W, Morris C, Guyton RA, Thourani VA. Elevated preoperative hemoglobin A1c level is associated with reduced long-term survival after artery bypass surgery. Ann Thorac Surg. 2008;86(5):1431-1437.

[28] Michael P. Robich, MD, MSPH, Alexander Iribarne, MD, MS, Bruce J. Leavitt, MD, David J. Malenka, MD, Reed D. Quinn, $M D$, Elaine M. Olmstead. Intensity of glycemic control affects long-term survival after coronary artery bypass graft surgery. Ann Thorac Surg. 2019;107(2):477-484.

[29] Nystrom T, Holzmann MJ, Eliasson B, Kuhl J, Sartipy U. Glycemic control in type 1 diabetes and long-term risk of cardiovascular events or death after coronary artery bypass grafting. J Am Coll Cardiol. 2015;66(5):535-543.

[30] Gozdzik A, Letachowicz K, Grajek BB, Plonek T, Obremska $M$, Jasinski M, Gozdzik W. Application of strain and other echocardiographic parameters in the evaluation of early and long-term clinical outcomes after cardiac surgery revascularization. BMC Cardiovasc Disord. 2019;19(1):189.

[31] Cihan HB, Erdil N, Nisanoğlu N, Çolak C, Erdil F, EgeE, Battaloglu B. Does type II diabetes mellitus increase mortality and morbidity in coronary artery bypass surgery? Turkish J Thorac Cardiovasc Surg. 2005;13:93-98.

[32] Nicolini, F., Santarpino, G., Gatti, G., Reichart, D., Onorati, F., Faggian, Dalen $M$, Khdabendeh $S$, Fischlein $T$, Maselli $D$, Nardella S, Rubino SA, Feo MS, Salsano A, Gherli R, Mariscalco G, Kinnunen EM, Ruggieri VG, Biancari F. Utility of glycated hemoglobin screening in patients undergoing elective coronary artery surgery: Prospective, cohort study from the E-CABG registry. International Journal of Surgery 2018; 53:354-359

[33] Kocogulları CU, Tekeli Kunt A, Aksoy R, Duzyol C, Parlar H, Saskın H. Hemoglobin A1c levels predicts acute kidney injury after coronary artery bypass surgery in non-diabetic patients. Braz J Cardiovasc Surg. 2017;32:83-89.

[34] Hertzberg D, Sartipy U, Holzmann MJ. Type 1 and type 2 diabetes mellitus and risk of acute kidney injury after coronary artery bypass grafting. Am Heart J. 2015; 170(5):895-902. 
How to cite this article: Aksoy R, Adademir T, Cevirme D, Yilmaz E, Sengor M, Koksal C, Rabus MB. The Effect of HbA1c Level on Gender-Specific Long-Term Morbidity and Mortality After Isolated Coronary Bypass in Poorly Controlled Diabetic Patients. Clin Exp Health Sci 2021; 11: 34-41. DOI: 10.33808/clinexphealthsci.782816 